\title{
Lexical processing and text integration of function and content words: Evidence from priming and eye fixations
}

\author{
A. RENÉ SCHMAUDER, ROBIN K. MORRIS, and DAVID V. POYNOR \\ University of South Carolina, Columbia, South Carolina
}

\begin{abstract}
The results of two experiments comparing processing of function words and content words are reported. In Experiment 1, priming was present for both related function and related content word pairs, as measured in lexical decision response times. In Experiment 2, participants' eye movements were monitored as they read sentences containing either a high- or a low-frequency function or content target word. Average word length and word frequency were matched across the function and content word conditions. Function words showed frequency effects in first-fixation and gaze duration that were similar to those seen for content words. Clear differences in on-line processing of function and content words emerged in later processing measures. These differences were reflected in reading patterns and reading time measures. There was inflated processing time in the phrase immediately following a lowfrequency function word, and participants made more regressions to the target word in this condition than in the other three conditions. The priming effects in lexical decision and the word frequency effects in initial processing measures in silent reading for both word types were taken as evidence of common lexical processing for function and content words. The observed differences in later processing measures in the eye-movement data were taken as evidence of differences in the role that the two word types have in sentence processing beyond the lexical level.
\end{abstract}

There are numerous linguistic distinctions between content and function words. Function words express or represent grammatical relations between content words, which denote actions, objects, entities, and properties. Function words have less lexical-semantic content than content words. They are defined primarily by the grammatical relation they express or the syntactic function they serve (Fries, 1940; Garrett, 1982; Levelt, 1989; Schmauder, 1996). The set of function words includes, but is not limited to, quantifiers, degree modifiers, auxiliaries, articles, and prepositions. Function words are not involved in productive compounding and derivation (Sweet, 1891), they do not contribute compositionally to meaning, and they form a relatively closed class in that new function words are rarely added to a language (Carlson \& Tanenhaus, 1984). Function words appear in syntactic positions in sentences (Abney, 1987) and have weak, unstressed, syllables (Cutler, 1993; Sweet, 1891). In comparison, the set of content words includes nouns, verbs, and adjectives and is an open class with new members coined regularly. Content words have strong syllables, participate in productive compounding and derivation, and have composi-

The authors thank Sachiko Matsumoto for her assistance in the data collection and data analyses for Experiment 1 . The authors also thank Charles Clifton, Keith Rayner, Alice Healy, and two anonymous reviewers for their helpful comments on earlier drafts of this manuscript. Correspondence should be addressed to R. K. Morris, Department of Psychology, University of South Carolina, Columbia, SC 29208 (email: morrisr@sc.edu). tional meaning (Carlson \& Tanenhaus, 1984; Sweet, 1891). The extent to which these linguistic distinctions translate to psychological representation and processing distinctions has not been explored fully. In this paper, we evaluate whether linguistic distinctions between function and content words are reflected in processing distinctions during lexical access and/or text integration. We report evidence from lexical decision times in a priming task and from eye-movement measures of processing time in a silent reading task in which word frequency was varied within word class.

Several scholars have proposed that function words and content words are subject to distinct lexical processes (e.g., Bradley, 1978; Bradley, Garrett, \& Zurif, 1980; Friederici, 1985; Rapp \& Caramazza, 1997). For instance, Sorensen, Cooper, and Paccia (1978) found that members of "minor" lexical categories (function words) have shorter duration when spoken in a sentence than members of "major" lexical categories (nouns, verbs, adjectives, and adverbs). Cutler $(1987,1993)$ has reported differences in syllabic stress for the two word classes (see also Cutler \& Butterfield, 1992; Grosjean \& Gee, 1987; Shattuck-Hufnagel, 1987). Spoken-language processing evidence suggests that function words and content words may be processed differently. Function and content words participate in different types of speech errors (e.g., Garrett, 1980; Stemberger, 1982), and bilingual code-switching data also indicate that function and content words behave differently (e.g., Joshi, 1985). These results could be taken as evidence of separate lexical processing for function 
and content words, or the differences may reflect functional differences at the level of sentence processing.

A common approach to differentiating content and function word processing has been to examine word frequency effects within the function word and content word classes. Word frequency effects have been demonstrated in virtually every standard measure of word recognition, including naming, lexical decision, tachistoscopic report, semantic categorization, same-different judgments, initial reading as measured by fixation duration, and measures of the early time course of brain activity as reflected in the early components of event-related potentials (ERPs). The ubiquity of frequency effects has been taken as evidence that word frequency is a basic dimension of lexical processing, with more frequent words processed quickly relative to less frequent words. However, when word class is considered in addition to word frequency, the results are less clear. Bradley (1978) found that lexical decisions to content words were sensitive to word frequency, whereas no frequency effect was observed for function words. Yet, frequency effects for function words have since been observed in English (e.g., Garnsey, 1985; Gordon \& Caramazza, 1982, 1983, 1985), French (Segui, Mehler, Frauenfelder, \& Morton, 1982), Spanish (Arnau \& Pelegrina, 1988), and Dutch (Kolk \& Blomert, 1985).

In addition to using word frequency effects as an indication of how function and content words are processed, research on eye movements during silent reading has revealed evidence of differential initial processing of function and content words in the eye-movement records of skilled readers. For example, Carpenter and Just (1983) monitored readers' eye movements and reported that participants fixated $83 \%$ of the content words but only $38 \%$ of the function words in technical reading material. However, frequency and length differences for function and content words make it hard to know whether this result reflects differences in word class per se. Also, function words typically are more predictable from sentence context than are content words. Predictability has been shown to influence word skipping during reading, even when length and frequency have been controlled (Balota, Pollatsek, \& Rayner, 1985; Ehrlich \& Rayner, 1981; Rayner \& Well, 1996). Likewise, as word frequency increases, the probability of word skipping increases (Reichle, Pollatsek, Fisher, \& Rayner, 1998), even when word length and word class (nouns only) are controlled (Rayner, Sereno, \& Raney, 1996). Finally, we know that the probability of skipping a word drops dramatically as word length increases: Rayner and McConkie (1976) reported that readers were four times more likely to fixate an eight-letter word than a two-letter word, on average. In sum, words tend to be skipped if they are frequent, short, or predictable, and function words that are high frequency, short, and predictable are often skipped (Holmes \& O'Regan, 1981; O'Regan, 1979; but also see O'Regan 1980, 1992). But this work does not tease apart the extent to which word skipping is due to word class as opposed to word length, frequency, or predictability. Nor is it clear to what extent these differences reflect lexicallevel processing as opposed to sentence-level processing. Also, we know of no studies comparing processing time, as opposed to probability of word skipping, for function and content words during silent reading in the absence of secondary tasks (cf. Moravcsik \& Healy, 1995).

At early stages of language comprehension, words are identified and relevant lexical information is activated. Once lexical information is activated, the language processing system must combine information provided by two or more words. Whether or not there are differences in lexical organization for function and content words that influence processing, the different roles function and content words have in a sentence may influence these phrase- and sentence-level processes. Function words serve a linking, syntactic, or relational function (Epstein, Rock, \& Zuckerman, 1960; Fries, 1940; Garrett, 1982; Glanzer, 1962; Levelt, 1989). They act to express relations among objects and entities denoted by content words, and they are critical to constructing an accurate discourse model (Morrow, 1985, 1986). Content words denote entities, states, actions, qualities, and characteristics, acting as designators in a working discourse model. Due to these different roles, once words' lexical representations have been activated, function and content words may have different influences on stages of processing reflecting sentence integration and message construction.

Several researchers have shown processing distinctions on a sentence level for function and content words in a letter-detection task (Abramovici, 1983; Drewnowski \& Healy, 1977, 1980; Greenberg \& Koriat, 1991; Haber \& Schindler, 1981; Healy, 1994; Koriat \& Greenberg, 1991, 1996; Moravcsik \& Healy, 1995; Saint-Aubin \& Poirier, 1997). Searching for a target letter in text passages, participants showed more letter-detection errors for letters in function words than for the same letters in content words. Abramovici (1983) extended the basic finding by showing that error detection was better for lexical verbs (e.g., "I was home") than for auxiliary verbs ("I was going home"), even though they were the same words. Similarly, Greenberg and Koriat (1991; cf. Moravcsik \& Healy, 1995) reported letter-detection error rates that were higher when words had function roles (as in "for better or worse") than when the same words had content word roles (as in "for or against"). Moravcsik and Healy (1995) found that letter detection was worse in words that have more familiar meaning than in words with less familiar meaning. The finding of differential letter-detection rates for letters in function and content words is consistent across studies. Several models have been proposed to account for differential letter detection performance (e.g., Koriat \& Greenberg, 1996; Moravcsik \& Healy, 1995; Saint-Aubin \& Poirier, 1997). However, the models interpret the results as reflecting different stages of processing, with some models suggesting that the effects occur at the lexical level, while other models support sentence-level processes as contributing to the effect. 
Haberlandt and Graesser (1989) examined self-paced reading times for function and content words as a function of serial position in a sentence. They reported that the later a word occurred in a sentence, the longer the processing time on that word, and that the increase was greater for content words than for function words. Noting that function and content words serve different roles in sentences, they then compared reading times for function words that have denotational functions, such as determiners and pronouns, against reading times for function words that have more of an organizational or relational function, such as prepositions and conjunctions. Haberlandt and Graesser reported that reading times increased more with sentence position for organizational/relational function words than for denotational function words. On the basis of this result, Haberlandt and Graesser suggested that as content words accrue in sentences, relations among them also accrue, leading to longer reading times for the function words that express those relations. This observation is consistent with the notion that there are observable processing differences between function and content words that occur beyond the lexical level.

\section{EXPERIMENT 1}

To examine whether lexical processes are similar for function and content words, priming effects were explored in the first experiment. Priming effects are well understood, since priming has long been used to study organization and access of the mental lexicon. Yet, priming has been examined almost exclusively with content word materials. Priming effects for content words are interpreted as reflecting a spread of activation between prime and target words (Neely, 1991). Supporting the likelihood that function words will show priming, there is evidence that associative learning of content and function words reflects shared properties, such as familiarity and meaning (Epstein et al., 1960). Therefore, we reasoned that if priming occurs for both function word targets and content word targets, then lexical processes as indexed by priming must be similar for function and content words.

The function word target condition prime-target pairs were either related (e.g., up-down) or unrelated (e.g., but-down). Content word target condition prime-target pairs were also related (e.g., love-hate) or unrelated (e.g., rule-hate). In all conditions, lexical decision (LD) time to the target member of the prime-target pair was the dependent measure. Assuming that the lexical processing reflected in lexical decision reaction times (LDRTs) is similar for function and content words, we predicted faster LDRTs for the target word in related pairs relative to unrelated pairs, regardless of target type (function vs. content). In contrast, if priming depends on lexical processing that is present for content words but not for function words, we predicted faster LDRTs for content target words in the related condition than in the unrelated condition. No relatedness effect on LDRTs was predicted in this case for function target words.

\section{Method}

Participants. Forty members of the University of South Carolina community participated. The participants had normal or correctedto-normal vision, were native speakers of English, and received course credit for their participation as part of the Psychology Department Human Participant Pool.

Materials. See Table 1 for sample stimuli. Thirty-two related function word prime-target pairs were created, such as $u p-d o w n$ (function related condition). The function word materials included words drawn from the following categories: preposition, conjunction, qualifier, determiner, light verb, and model auxiliaries. The function unrelated condition was created by pairing the same function word target (e.g., down) with an unrelated function word prime that was matched in length (within two characters) and frequency (Francis \& Kučera, 1982) to the related function word prime, such as but-down. Most of the function word pairs had a paradigmatic relation (e.g., up-down), but some pairs had a syntagmatic relation (e.g., every-other). Syntagmatic pairs were words that could occur adjacent to each other, either because the words were members of syntactic categories licensed by English grammar to co-occur (e.g., every-other, as in "every other seat should be filled") or because the words frequently co-occur in question constructions (e.g., wherethere, as in "Put it down. Where? There"). The function word stimuli were run in a block together with 32 prime-nonword target pairs. Nonword targets were created from real function words by changing one letter to yield a pronounceable nonword that conformed to the rules of English orthography. Thirty-two related content word prime-target pairs were selected from materials used by Sereno and Rayner (1992), and these pairs formed the content related condition, such as love-hate. The content unrelated condition was created by replacing the related prime with an unrelated, length- and frequency-matched prime, such as rule-hate (see Sereno \& Rayner, 1992 , for details on the associative relation for the content word materials). Content word prime-target pairs were run in a block with 32 prime-nonword target pairs. These nonword targets were created from real content words by changing one letter to create a pronounceable nonword that conformed to the rules of English orthography. Nonword target pairs were different for the function and content blocks.

All participants saw each target word following either its related or its unrelated prime, such that they viewed an equal number of related and unrelated pairs for the experimental items. They saw 32 function word prime-target pairs ( 16 related and 16 unrelated) mixed with 32 filler prime-nonword target pairs in the function block and 32 content word prime-target pairs mixed ( 16 related and 16 unrelated) with 32 filler prime-nonword target pairs in the content block. Thus, each participant saw a total of 128 pairs. Items in each block were presented in a different random order for each participant. Block order was counterbalanced across participants.

Procedure. The participants were seated in front of a computer monitor with a response-key apparatus in front of them. They were instructed that, on each trial, they would see first a fixation cross followed by presentation of an uppercase word that they were to read silently to themselves. They were told that when they saw the next stimulus, also uppercase, they were to decide as quickly and accurately as possible whether that word was a real word in English.

Table 1

Mean Lexical Decision Reaction Times

(LDRTs; in Milliseconds) in Experiment 1

\begin{tabular}{lccccc}
\hline & \multicolumn{2}{c}{ Function Word } & & \multicolumn{2}{c}{ Content Word } \\
\cline { 2 - 3 } \cline { 5 - 6 } & Prime-Target & LDRT & & Prime-Target & LDRT \\
\hline Related & UP-DOWN & 626 & & LOVE-HATE & 601 \\
Unrelated & BUT-DOWN & 643 & & RULE-HATE & 630 \\
Facilitation & & 17 & & & 29 \\
\hline
\end{tabular}


The participants were instructed to push the "Yes it's a real word" button if the target word was a real word in English and the "No it isn't a real word" button if the target word was not a real word in English. They were told that error feedback would be presented. Finally, speed and accuracy were again stressed.

After a practice block of 12 trials (a mixture of function and content word and nonword trials), the participants began the experiment. At the start of each trial, a small fixation cross was presented at the center of the screen for $500 \mathrm{msec}$. A 0 -msec interstimulus interval (ISI) preceded presentation of the prime word, which was presented in uppercase letters and which remained on the screen for $200 \mathrm{msec}$. A 50-msec ISI followed prime presentation, and the LD target was then presented centered on the screen in uppercase letters until the participant responded. The PC controlling the Experiment recorded the participants' responses and response latencies to the target words. If a participant's response was correct, a 0-msec intertrial interval (ITI) occurred, and the presentation of the fixation cross began the next trial. If a participant made an incorrect response, the word ERROR appeared on the screen, in uppercase white letters, for $1,000 \mathrm{msec}$ prior to the onset of the first event of the next trial.

\section{Results}

RTs shorter than $200 \mathrm{msec}$ or longer than $2,500 \mathrm{msec}$ were considered response errors and were replaced with the cutoff values. This affected fewer than $3 \%$ of the data. Mean LDRT data are reported in Table 1. Incorrect $\mathrm{LD}$ responses averaged $3.5 \%$, distributed evenly across conditions.

As seen in Table 1, there were priming effects for both the function and content target words. There was a reliable main effect of related/unrelated prime on LDRTs $\left[F_{1}(1,39)=19.89, M S_{\mathrm{e}}=1,034, p<.001 ; F_{2}(1,62)=\right.$ $\left.13.78, M S_{\mathrm{e}}=1,097, p<.001\right]$. A planned contrast showed that the 17-msec priming effect in the function word conditions was reliable $\left[F_{1}(1,39)=5.18, M S_{\mathrm{e}}=1,104, p<\right.$ $\left..03 ; F_{2}(1,31)=5.7293, M S_{\mathrm{e}}=774, p<.03\right]$. In the content-word conditions, LDRTs were $29 \mathrm{msec}$ faster in the related condition than in the unrelated condition $\left[F_{1}(1,39)\right.$ $=18.03, M S_{\mathrm{e}}=898, p<.001 ; F_{2}(1,31)=8.12, M S_{\mathrm{e}}=$ $1,420, p<.008]$. The main effect of function versus content was reliable in the overall analyses $\left[F_{1}(1,39)=4.61\right.$, $M S_{\mathrm{e}}=3,127, p<.04 ; F_{2}(1,62)=3.81, M S_{\mathrm{e}}=3,229$, $p=.05]$, reflecting the longer RTs for function word targets $(635 \mathrm{msec})$ than for content word targets $(616 \mathrm{msec})$. The interaction between word type (function/content) and relatedness was not reliable $\left[F_{1}(1,39)=1.37, M S_{\mathrm{e}}=967\right.$, $\left.p>.2 ; F_{2}(1,62)<1, M S_{\mathrm{e}}=1,097, p>.3\right]$.

\section{Discussion}

The results revealed priming within the function word vocabulary, supporting the hypothesis that spread of activation between lexical items occurred in the function word vocabulary as well as in the content word vocabulary. We can conclude that there was a spread of activation between our related primes and function word targets that was not present between our unrelated primes and function word targets.

\section{EXPERIMENT 2}

The existence of reliable priming in the function word vocabulary demonstrated in Experiment 1 suggests that function words and content words are subject to similar principles of lexical activation and processing. Given this result, we now turn to another lexical factor for which there are robust and well-documented effects in the content word processing literature, printed word frequency.

Forster (1981) argued that word frequency was a basic principle of lexical organization, and word frequency effects are observed for content words in a variety of tasks, including fluent silent reading (e.g., Inhoff, 1984; Inhoff \& Rayner, 1986; Rayner \& Duffy, 1986). However, the literature evaluating word frequency effects in the function word class has produced mixed results, and we know of no data regarding word frequency effects within the function word class in silent reading without a secondary task. Therefore, in Experiment 2, we examined eye movements during silent reading of sentences that contained either a low- or a high-frequency function word and sentences that contained either a low- or a high-frequency content word. We examined the effects of word frequency on lexical access of target content and function words by looking at initial processing time on these words. If function and content words are represented similarly in the mental lexicon, then word frequency should influence lexical access of both function and content words, with more frequent words fixated for less time than words that are less frequent. Also, there should be no interaction between word class and word frequency.

Past eye-movement studies that have examined differences between function and content words have focused on short words and have emphasized differential patterns of word skipping between the two word classes. However, these studies have often confounded word frequency, word length, and word class. In Experiment 2, we used longer words and controlled for differences in word length and word frequency across word class. If the word-skipping effects reported in the earlier literature are due to differences in word class or to differences in linguistic predictability between the two classes, then we would expect to see more skipping of function words than of content words in Experiment 2.

Experiment 2 also investigated how processing of function and content words differs during stages of sentence processing subsequent to lexical access. Function words serve a linking or relational role between content words, whereas content words denote actions, entities, states, and characteristics. To the extent that these differences affect lexical access, we would expect to see differences in initial processing on the target word. If these linguistic differences lead to processing differences beyond lexical access, we would expect to find effects of word class in measures reflecting text integration processes, such as rereading time and frequency of rereading.

\section{Method}

Participants. Thirty-four members of the University of South Carolina community participated in this experiment. All participants were native speakers of English with normal uncorrected vision and received course credit for their participation.

Procedure. The participants' eye movements were monitored as they silently read individual sentences presented one at a time on a 
computer screen. They were instructed to read for comprehension and were told that the experimenter would ask yes/no comprehension questions after some of the sentences. A bite plate was prepared for each participant to minimize head movements during eye-movement monitoring, and the eye-tracking system was then calibrated for each participant. The participants read six practice sentences and then were allowed to ask any questions that they might want answered before proceeding with the data collection phase of the experiment. This process took approximately $5 \mathrm{~min}$.

The participants read 20 experimental sentences and 114 filler sentences. Sentences were presented in a different random order for each participant. After reading each sentence, the participant pressed a button, and the sentence was removed from the screen and replaced with a sequence of five fixation boxes. The participants indicated that they were ready for the next sentence by looking at the leftmost box. The experimenter controlled the presentation. Comprehension questions were asked orally while the fixation boxes were on the screen, and feedback was given to the participants regarding comprehension accuracy. All participants performed at $90 \%$ or higher on the comprehension questions. The entire experimental session lasted approximately $30 \mathrm{~min}$.

Apparatus. Eye movements were monitored by a Fourward Technologies Dual Purkinje Image Eyetracker. Viewing was binocular with right eye movements monitored. The eye tracker was interfaced with an IBM model 80 computer, and sentences were presented on an IBM VGA monitor set $79 \mathrm{~cm}$ from the participant. Four characters of text subtended $1^{\circ}$ of visual angle. Sentences were presented one at a time on the screen as a single line of text that did not exceed 70 character spaces.

Materials. We selected 20 function words with word length ranging from 4 to 10 characters and a mean length of 5.3 characters. Inclusion in the function word set was based on the grammatical functions that the words served and came from a variety of different parts of speech. Half of the function words were high frequency (ranging from 221 to 580 words per million [WPM]; mean frequency $=425 \mathrm{WPM}$ ), and half of the function words were low frequency (ranging from 3 to 47 WPM; $M=18$ WPM). Low-frequency words were paired with high-frequency words such that each pair was matched in word length to within one character. A length-matched set of 20 content words was then selected: 10 were low frequency (range $=3-49 ; M=19$ ), and 10 were high frequency (range = $222-583 ; M=426$ ). The word length for the content words ranged from 4 to 9 characters, with a mean length of 5.2 characters.

There were 20 sentence frames: 10 function word frames and 10 content word frames. For each sentence frame, there were two possible target words, a high-frequency word or a low-frequency word. The sentence context preceding the target word was semantically neutral with respect to the meaning of the word. Each participant saw each sentence frame only once. Thus, each participant saw half the function word sentences with a high-frequency function word (e.g., "As we looked across the crowd ...") and half with a low-frequency function word (e.g., "As we looked amidst the crowd ..."), and likewise for the content word sentences. An example of a function word sentence is, "As we looked across (282)/ amidst (3) the crowd we could see Dad's bright red jacket." An example of a content word sentence is, "The old-fashioned method (284)/helmet (3) was far more effective than any modern one."

The target word always appeared early in the sentence, and the average ordinal position of the word did not differ between the content and function word sentences. We purposefully avoided using sentences in which the position of the target word would coincide with a position known to create structural processing difficulty. In an experiment comparing word-skipping rates for function and content words during silent reading, O'Regan (1979) placed the word the and short, high-frequency verbs, such as had, in identical posi- tions in sentence contexts. The sentences continued either with an adverbial phrase modifying hunting, as in "The bear that Joe was hunting the other day was caught," or with a main verb phrase, as in "The bear that Joe was hunting had been seen." Unfortunately, placing the critical words in sentence contexts identical up to that point created structural attachment differences known to create differences in on-line processing in a manner that likely contributed to the effects reported by O'Regan (e.g., Frazier, 1987; MacDonald, Pearlmutter, \& Seidenberg, 1994; Schmauder \& Egan, 1998; Trueswell \& Tanenhaus, 1994). To avoid creating this situation in our own materials, we chose to use distinct sentence frames for function and content words. This permitted us to avoid introducing structural ambiguities known to cause processing difficulty that would have increased processing times on the words of interest. ${ }^{1}$

\section{Results}

Initial processing of the target word was assessed by looking at word skipping, first-fixation duration, and gaze duration. Word skipping was calculated as the percentage of trials in which the reader skipped the target in their first pass through the sentence. First-fixation duration is a measure of the reader's initial fixation time on a word, regardless of the total number of fixations made on that word. It does not include any subsequent fixations on the word (consecutive or regressive). Gaze duration is the sum of consecutive fixation durations on the reader's first pass through a word. It includes first-fixation duration but does not include any fixations on the word that occur after the reader has left the word for the first time. In addition, we examined text integration and reanalysis effects. Immediate integration effects were evaluated by looking at the duration of the first fixation following the target word (immediate integration time). We assessed the participants' rereading behavior in the following ways. We looked at the frequency with which the participants looked back to the target word given that they had initially processed it and moved on (regressions in), and we looked at the total amount of time that the participants spent on the target word, including gaze duration and the duration of any regressive fixations to the word (total time). Given that there were differences in initial processing time on the targets, we also report the time spent rereading the target words with initial processing time removed (second-pass reading time). Cases in which the participants did not reread the target word were included as zeros in this analysis. Finally, we computed the frequency with which the participants made regressions from the region immediately following the target word. This region began with the first word following the target word and ended with the final word of that phrase. Fixations that were less than $120 \mathrm{msec}$ or more than $1,000 \mathrm{msec}$ in duration were omitted from the analyses. This resulted in a net loss of $4 \%$ of the data.

Initial target word processing. A summary of initial processing time results is displayed in Table 2.

As predicted, the participants looked longer at lowfrequency words than at high-frequency words regardless of word class. These effects were substantiated as a main 
Table 2

Initial Processing Measures on the Target Word in Experiment 2

\begin{tabular}{|c|c|c|c|}
\hline Condition & $\begin{array}{c}\text { First-Fixation } \\
\text { Duration }(\mathrm{msec})\end{array}$ & $\begin{array}{c}\text { Gaze } \\
\text { Duration (msec) }\end{array}$ & $\begin{array}{c}\% \text { of Target } \\
\text { Words Skipped }\end{array}$ \\
\hline \multicolumn{4}{|l|}{ Function Word } \\
\hline Low frequency & 300 & 347 & 15.7 \\
\hline High frequency & 259 & 301 & 18.7 \\
\hline \multicolumn{4}{|l|}{ Content Word } \\
\hline Low frequency & 280 & 317 & 13.7 \\
\hline High frequency & 253 & 279 & 21.6 \\
\hline
\end{tabular}

effect of word frequency [first-fixation duration: $F_{1}(1,33)$ $=11.33, M S_{\mathrm{e}}=3,492, p<.01 ; F_{2}(1,18)=14.09, M S_{\mathrm{e}}=$ 766, $p<.001$; gaze duration: $F_{1}(1,33)=13.82, M S_{\mathrm{e}}=$ $\left.4,274, p<.01 ; F_{2}(1,18)=7.61, M S_{\mathrm{e}}=2,660, p<.01\right]$, with no interaction between frequency and word class (all $F_{\mathrm{s}}<1$ ).

There was also a main effect of word class in the participant analysis of the gaze duration data, with a mean gaze time for function words of $314 \mathrm{msec}$ versus $298 \mathrm{msec}$ for content words $\left[F_{1}(1,33)=5.53, M S_{\mathrm{e}}=4,243, p<.05\right]$. This effect was not reliable in the items analysis $\left[F_{2}(1,18)\right.$ $\left.=2.40, M S_{\mathrm{e}}=3,646, p=.14\right]$.

Interestingly, the word-skipping data revealed an effect of word frequency, such that high-frequency words were skipped more frequently than low-frequency words $\left[F_{1}(1,33)=5.58, M S_{\mathrm{e}}=0.018, p<.02 ; F_{2}(1,18)=\right.$ $\left.2.95, M S_{\mathrm{e}}=0.012, p<.10\right]$. But there was no evidence of a difference between content and function words $(F \mathrm{~s}<1)$, and there was no interaction between word class and word frequency $(F \mathrm{~s}<1)$.

Text integration and reanalysis measures. The pattern of results shifts somewhat as we examine the data from the text integration and reanalysis measures presented in Table 3. In first-fixation and gaze duration, measures that are strongly influenced by lexical access, word frequency effects dominated the data. Frequency effects also were present in the word-skipping data. In the immediate integration measure (the duration of the first fixation following the target word, also called spillover), both word frequency and word class influenced processing time. As in the first-fixation and gaze duration data, processing times were longer for low-frequency words than for high-frequency words $\left[F_{1}(1,33)=6.06, M S_{e}=\right.$ $\left.2,281, p=.02 ; F_{2}(1,18)=6.88, M S_{\mathrm{e}}=650, p=.02\right]$, replicating findings of Rayner and Duffy (1986). However, the participants also spent more time on the word immediately following a function word than on the word immediately following a content word $\left[F_{1}(1,33)=7.60\right.$, $M S_{\mathrm{e}}=1,346, p=.01 ; F_{2}(1,18)=4.0, M S_{\mathrm{e}}=916, p=$ $.06]$, and word class interacted with word frequency $\left[F_{1}(1,33)=4.81, M S_{\mathrm{e}}=2,499, p=.03 ; F_{2}(1,18)=\right.$ $\left.4.47, M S_{\mathrm{e}}=650, p<.05\right]$. As you can see in Table 3, this interaction is driven by inflated processing time following low-frequency function words.

In the other text integration and reanalysis measures presented in Table 3, the word class variable dominated the pattern of results. The participants spent more total processing time on function words than on content words $\left[F_{1}(1,33)=14.36, M S_{\mathrm{e}}=9,771, p<.001 ; F_{2}(1,18)=\right.$ $\left.4.68, M S_{\mathrm{e}}=9,603, p<.05\right]$, more total time on lowfrequency words than on high-frequency words $\left[F_{1}(1,33)\right.$ $=4.68, M S_{\mathrm{e}}=11,059, p<.05 ; F_{2}(1,18)=3.49, M S_{\mathrm{e}}=$ $6,512, p<.07]$, and there was no interaction $(F \mathrm{~s}<1)$. However, total time is the sum of initial processing fixations and regressive fixations on which the reader returns to the word after having left it. By examining second-pass reading time, we can assess the extent to which total time differences reflected differences in rereading on the target word, uncontaminated by initial processing time differences. The second-pass measure showed a simple main effect of word class, with longer times on function words than on content words $\left[F_{1}(1,33)=12.25, M S_{\mathrm{e}}=4,135\right.$, $\left.p=.001 ; F_{2}(1,18)=3.79, M S_{\mathrm{e}}=3,983, p=.07\right]$. There were no other reliable effects (all $F \mathrm{~s}<1$ ).

There were also word class effects when we looked at the frequency with which the participants returned to the target word (see Table 3). The participants made more frequent regressions to reread function words than to reread content words $\left[F_{1}(1,33)=18.27, M S_{\mathrm{e}}=177, p<\right.$ $\left..001 ; F_{2}(1,18)=4.04, M S_{\mathrm{e}}=240, p=.06\right]$. There was no main effect of word frequency and no interaction. Furthermore, when we looked to the phrase immediately following the target word, we found that there were more regressions out of that region when it followed a function word than when it followed a content word $\left[F_{1}(1,33)=\right.$ $23.36, M S_{\mathrm{e}}=281, p<.0001 ; F_{2}(1,18)=9.73, M S_{\mathrm{e}}=$ $171, p<.01]$. When we compared the number of regres-

Table 3

Text Integration and Reanalysis Measures on the Target Word in Experiment 2

\begin{tabular}{ccccc}
\hline $\begin{array}{c}\text { Condition } \\
\text { Integration (msec) }\end{array}$ & $\begin{array}{c}\text { Total Time } \\
(\mathrm{msec})\end{array}$ & $\begin{array}{c}\text { Second-Pass } \\
\text { Time (msec) }\end{array}$ & $\begin{array}{c}\text { Regressions to } \\
\text { Target Word (\%) }\end{array}$ \\
\hline $\begin{array}{c}\text { Function Word } \\
\text { Low frequency }\end{array}$ & 296 & 440 & 97 & 21.4 \\
$\quad$ High frequency & 257 & 391 & 93 & 19.6 \\
$\begin{array}{c}\text { Content Word } \\
\text { Low frequency }\end{array}$ & 260 & 366 & 50 & 8.7 \\
High frequency & 258 & 336 & 63 & 12.8 \\
\hline
\end{tabular}

Note-Immediate integration was measured by the duration of the first fixation after the participant had fixated the target word. Regressions to the target word are reported as the percentage of trials in which the target word was fixated by means of a regressive saccade. 
sions to the target word with the number of regressions leaving the posttarget region, we found that the function word regressions appeared to come mainly from regressions leaving the immediately following region (regression to the target word $=20.5$; regressions from posttarget region $=20.3$ ). This was not true for the content word conditions (regressions to the target word $=10.8$; regressions from the posttarget region $=6.4$ ). This suggested that the rereading in the function word condition was directly related to the linking function expressed by that word.

\section{Discussion}

A number of unique results regarding the access and utilization of function words in on-line processing have emerged from this experiment. First, we have shown a strong and consistent effect of word frequency in the initial processing of function words and content words, with no evidence that this effect differs reliably for the two word types. Second, we have no evidence that readers are more likely to skip function words than content words when word length and word frequency are equated across the two word classes. Both word frequency and word class influenced immediate text integration as measured by the duration of the first fixation after the participant left the target word. The duration of the first fixation immediately after a low-frequency function word was inflated relative to that after a high-frequency function word or to that after content words regardless of word frequency. Differences between the two word classes were more pronounced in the reanalysis measures. The participants reread function words more frequently than content words and spent more total reading time on function words than on content words, even when initial processing time differences were factored out. Furthermore, the pattern of rereading differed across the two classes of words. That is, the rereading of the function word was consistently prompted by the information contained in the phrase immediately following it. This was not so for the content words. Together, these results reveal a dissociation between lexical access and text integration effects for function and content words. Access was strongly influenced by word frequency in both word classes. When we looked at text integration, we found pronounced differences between function and content word processing and diminished effects of word frequency.

\section{GENERAL DISCUSSION}

The results of the two experiments revealed common lexical processing characteristics across function and content words. Experiment 1 demonstrated that both content and function words are vulnerable to priming effects, reflecting spread of activation in the lexicon; Experiment 2 demonstrated that the time to access function and content words in an on-line reading task is sensitive to differences in word frequency. Both function and content words appear to be processed similarly at the lexical level, with priming and word frequency effects present for both function and content words. The pattern of results we obtained from measures sensitive to lexical processing did not support the existence of unique lexical access mechanisms for function and content words. In addition, processing measures from the eye-movement record that are sensitive to lexical integration and reprocessing revealed distinctions between function and content words that contrasted with the effect of word frequency at the lexical level and reflected the relational function served by the function words.

The word frequency effects in initial processing time in Experiment 2 are consistent with prior eye-movement studies that have examined processing time on nouns (Inhoff \& Rayner, 1986; Rayner \& Duffy, 1986; Rayner et al., 1996; Vitu, 1991). However, this is the first demonstration of frequency effects in fixation time data from reading of function words. Our word-skipping data for function words also did not differ from that of content words, and the pattern is consistent with prior studies that demonstrated effects of word frequency in the probability of skipping nouns (Rayner et al., 1996). In addition, we found priming for both function and content words in Experiment 1. Taken together, these results do not add specific support to proposals that function and content words are stored in distinct lexicons (e.g., Bradley, 1978; Bradley et al., 1980; Friederici, 1985; Rapp \& Caramazza, 1997). We refer to this class of proposals as vocabularytype proposals (Schmauder, 1992). Vocabulary-type proposals predicted reliable word class interactions in target word processing in both experiments, and no such interactions were observed.

In Experiment 1, we observed longer LDRTs for function words than for content words. This pattern has been observed in earlier reports of LD data (e.g., Bradley, 1978; Gordon \& Caramazza, 1985). We think that this difference reflects the fact that the information stored with function word lexical representations differs from the information stored with content word lexical representations (Schmauder, 1992, 1996; Taft, 1990). Function words include specification of relational information, whereas content words have more lexical-semantic content. This difference in amount and kind of independent lexical-semantic content across word classes is what led to the difference between function and content word processing in the lexical decision task. The lexical decision task probably involves either an explicit or an implicit assessment of how meaningful a word is (Balota \& Chumbley, 1984). Thus, when presented with function or content words in isolation and asked to make a lexical decision, the participants responded more slowly to function words, which were words with less lexical-semantic content (Schmauder, 1996; Taft, 1990). A similar explanation has been offered to explain the role of meaning in associative learning of word stimuli (e.g., Epstein et al., 1960; Kohler, 1929; Miller \& Selfridge, 1950; Sheffield, 1946). Epstein et al. (1960) performed a paired-associate experiment that demonstrated that learning was better for nouns, 
which were both meaningful and familiar, than for conjunctions and prepositions, which had less meaning but were familiar. In Experiment 2, differences in initial processing time between function and content words were not as robust. This makes sense given that, in the reading task, this meaningfulness assessment is not required, as it was in the lexical decision task.

Word class did not interact in any measures of earlier lexical-level processing in Experiment 1 or Experiment 2. Dell (1990) suggested that function words are stored with fragments of syntactic structure, but content words are not (see also Lapointe \& Dell, 1989). In this account, function words are accessed from the lexicon together with their associated syntactic structure fragments, and the structure fragments then are incorporated into the working syntactic structure. In contrast, content words' lexical representations are retrieved at lexical access, and an additional process of lexical insertion associates the content word representations with the appropriate structural position that was constructed by distinct syntactic-structurebuilding processes (cf. Garrett, 1982; Levelt, 1989). The distinction is that content words require lexical insertion into existing syntactic structure positions, whereas function words come with their own structure fragments, which in turn are attached to existing structure, without lexical-insertion functions being invoked. This proposal is consistent with the fact that word class did not interact with lexical-level factors in Experiments 1 and 2. Dell's proposal could be seen as advocating processing differences for function and content words at stages of sentence integration and reprocessing.

In Experiment 2, measures sensitive to lexical integration and reprocessing did show differential effects of word class. We note that these measures most likely reflect different roles that function words and content words play in creating the discourse-level representation. The first fixation made after target words were read was longer following low-frequency function words than following high-frequency function words or following high- or lowfrequency content words. Also, function words were reread more often and for more time than were content words, regardless of frequency. Rereading of function words was triggered by reading of the next phrase, supporting the claim that function words have a relational function and that, in order to create an integrated text representation, readers sometimes must reread the function word once they have established what entities that function word relates.

Consider the fact that people fail to detect letters in function words more often than in content words. In Healy's unitization model (Drewnowski \& Healy, 1977, 1980; Healy, 1994; Moravcsik \& Healy, 1995), word frequency determines how quickly a word is identified. High-frequency words are identified quicker than their component letters are identified. Thus, according to the unitization model, word frequency rather than word function gives rise to letter detection errors for function words. Koriat and Greenberg (1991, 1996; Greenberg \& Koriat, 1991) claimed that this pattern reflected relatively less- accessible representations for function words than for content words. In their structural model of reading, function words' representations are accessed quickly and are used to "establish a structural frame for the sentence" (Koriat \& Greenberg, 1994, p. 351; cf. Dell, 1990). The representations of function words then fade, making their component letters less available and resulting in more letter-detection errors.

We found word frequency effects for function words at lexical access in Experiment 2, supporting the unitization model. Also, the participants were more likely to reread function words, and they spent more time rereading function words than content words. This pattern is consistent with Koriat and Greenberg's structural model of reading: If function words' representations have faded after being used to set sentence structure, then those words' lexical representations will have to be reactivated when relational information is needed. This reactivation will take processing time and will require rereading function words. This rereading may indicate use of the relational information denoted in function words' lexical representations to direct incorporation of discourse entities denoted by content words into the working discourse representation (also see Aaronson \& Ferres, 1983a, 1983b; Haberlandt \& Graesser, 1989). Thus, to the extent that the present data are relevant to either model of letter detection, we found that word frequency affected initial stages of lexical processing (consistent with the unitization model), whereas word class affected subsequent text integration processes (consistent with the structural model).

Function words that are frequent, short, and predictable are often skipped (Balota et al., 1985; Carpenter \& Just, 1983; Ehrlich \& Rayner, 1981; O'Regan, 1979; Rayner \& Well, 1996). In the present data, the participants skipped high-frequency words more often than low-frequency words, consistent with Rayner et al. (1996). However, we obtained no evidence that there are differences in the likelihood of skipping function and content words. This appears to be inconsistent with a number of other eye-movement studies that have reported evidence that readers are more likely to skip function words than content words (e.g., Carpenter \& Just, 1983; Henderson \& Ferreira, 1993; Holmes \& O'Regan, 1981; O’Regan, 1975, 1979; but cf. O'Regan, 1992). However, our study differed from earlier reports in several crucial ways. First, we orthogonally varied word frequency and word class. That is, our study included both high-and low-frequency function words and high- and low-frequency content words. Previous studies either have confounded these two variables or have looked only at processing of highfrequency function words. Second, our high-frequency conditions were equated across word class. That is, we selected high-frequency function words in order to be able to find content words of equivalent frequency. The most familiar function words in English (e.g., the, as, $b u t)$ are far more frequent than the highest frequency content words. While several of the earlier studies compared processing of high-frequency function and content words, 
the high-frequency function words used were typically of much higher frequency than were the high-frequency content words. Finally, we equated word length across the two word sets, and we avoided using extremely short words (those with three letters or fewer). Our stimuli varied in word length from 4 to 10 characters, with an average length of slightly more than 5 characters, and the participants skipped roughly $20 \%$ of the target words overall. This skipping rate is consistent with previously reported skipping rates for content words. Readers skip extremely high-frequency, extremely short function words far more frequently, with some reports as high as $80 \%$.

O'Regan (1975) argued that function words are skipped more frequently than content words because structural aspects of the language make function words highly predictable. Our data are inconsistent with that general claim. However, that explanation may hold for the word the in the sentence position that $O$ 'Regan tested. There are two reasons why O'Regan may have found a higher rate of word skipping for the than for other words. First, the frequency of the is higher than the frequency of the highfrequency verbs that he used, and that frequency disparity may have contributed to the differences in word skipping that O'Regan observed. Second, O'Regan placed the target words in his study at a structurally ambiguous point that strongly predicted an upcoming noun phrase. The word the is a short, high-frequency marker that a noun will appear next, and this was consistent with what the syntactic structure called for, so word skipping resulted. In our materials, function word targets and content word targets were placed in sentence contexts that did not encourage differences in predictability due to word class, and we did not find such effects. In addition, our initial target word processing time data do not support a predictability explanation. If function words were more predictable than content words, we should have seen shorter processing time on function words than on content words, and we did not.

In summary, in the research reported here, the present studies demonstrated similarities in early stages of lexical processing for function and content words and differences in later integrative text processing of function and content words. Function words and content words are most likely stored and accessed similarly, but the different roles the two word types have in language influence processes that integrate words during text processing and construction of a discourse representation.

\section{REFERENCES}

Aaronson, D., \& Ferres, S. (1983a). Lexical categories and reading tasks. Journal of Experimental Psychology: Human Perception \& Performance, 9, 675-699.

Aaronson, D., \& Ferres, S. (1983b). A model for coding lexical categories during reading. Journal of Experimental Psychology: Human Perception \& Performance, 9, 700-725.

ABNEY, S. P. (1987). The English noun phrase in its sentential aspect. Unpublished doctoral dissertation, Massachusetts Institute of Technology.
ABramovicI, S. (1983). Errors in proofreading: Evidence for syntactic control of letter processing? Memory \& Cognition, 11, 258-261.

Arnau, J., \& Pelegrina, M. (1988). Análisis de la discrimanación y decisión en el reconocimiento de palabras mediante la técnica del tiempo de reacción y medidas derivadas del modelo de la TDS [Discrimination and decision in word recognition by means of the reaction time technique and measures derived from the signal detection theory (SDT) model]. Psicologica, 9, 27-42.

Balota, D. A., \& Chumbley, J. I. (1984). Are lexical decisions a good measure of lexical access? The role of word frequency in the neglected decision stage. Journal of Experimental Psychology: Human Perception \& Performance, 10, 340-357.

Balota, D. A., Pollatsek, A., \& Rayner, K. (1985). The interaction of contextual constraints and parafoveal visual information in reading. Cognitive Psychology, 17, 364-390.

BRADLEY, D. C. (1978). Computational distinctions of vocabulary type. Unpublished doctoral dissertation, Massachusetts Institute of Technology.

Bradley, D. C., Garrett, M., \& Zurif, E. B. (1980). Syntactic deficits in Broca's aphasics. In D. Caplan (Ed.), Biological studies of mental processes (pp. 269-286). Cambridge, MA: MIT Press.

Carlson, G., \& Tanenhaus, M. K. (1984). Lexical meanings, structural meanings, and concepts. In D. Testen, V. Mishra, \& J. Drogo (Eds.), Papers from the Parasession on Lexical Semantics (pp. 3952). Chicago: Chicago Linguistic Society.

CARPENTER, P. A., \& JUST, M. A. (1983). What your eyes do while your mind is reading. In $\mathrm{K}$. Rayner (Ed.), Eye movements in reading: Perceptual and language processes (pp. 275-307). New York: Academic Press.

CUTLER, A. (1987). Auditory lexical access: Where do we start? In W. Marslen-Wilson (Ed.), Lexical representation and process (pp. 342356). Cambridge, MA: MIT Press.

CutLer, A. (1993). Phonological cues to open- and closed-class words in the processing of spoken sentences (Special issue: Sentence processing III). Journal of Psycholinguistic Research, 22, 109-131.

Cutler, A., \& ButTerfield, S. (1992). Rhythmic cues to speech segmentation: Evidence from juncture misperception. Journal of Memory \& Language, 31, 218-236.

DELL, G. (1990). Effects of frequency and vocabulary type on phonological speech errors. Language \& Cognitive Processes, 5, 313-349.

DrewnowsKI, A., \& HeALY, A. F. (1977). Detection errors on the and and: Evidence for reading units larger than the word. Memory \& $\mathrm{Cog}$ nition, 5, 636-647.

DREWNOWSKI, A., \& HeALY, A. F. (1980). Missing -ing in reading: Letter detection errors on word endings. Journal of Verbal Learning \& Verbal Behavior, 19, 247-262.

EhrLICH, S. F., \& RAYNER, K. (1981). Contextual effects of word perception and eye movements during reading. Journal of Verbal Learning \& Verbal Behavior, 20, 641-655.

Epstein,W., Rock, I., \& ZuCKerman, C. B. (1960). Meaning and familiarity in associative learning. Psychological Monographs: General \& Applied, 74, 1-22.

FORSTER, K. I. (1981). Frequency blocking and lexical access: One mental lexicon or two? Journal of Verbal Learning \& Verbal Behavior, 20, 190-203.

FrANCIS, W. N., \& KuČera, H. (1982). Frequency analysis of English usage: Lexicon and grammar. Boston: Houghton Mifflin.

Frazier, L. (1987). Sentence processing: A tutorial review. In M. Coltheart (Ed.), Attention and performance XII: The psychology of reading (pp. 559-586). Hillsdale, NJ: Erlbaum.

FRIEDERICI, A. D. (1985). Levels of processing and vocabulary types: Evidence from on-line comprehension in normals and agrammatics. Cognition, 19, 133-166.

Fries, C. C. (1940). American English grammar. New York: AppletonCentury-Crofts.

GARNSEY, S. M. (1985). Function words and content words: Reaction time and evoked potential measures of word recognition (University of Rochester Cognitive Science Tech. Rep. No. URCS 29). Rochester, NY: University of Rochester. 
GARRETT, M. F. (1980). Levels of processing in sentence production. In B. Butterworth (Ed.), Language production (pp. 177-220). New York: Academic Press.

GarretT, M. F. (1982). Production of speech: Observations from normal and pathological language use. In A. Ellis (Ed.), Normality and pathology in cognitive functions (pp. 19-76). London: Academic Press.

GLANZER, M. (1962). Grammatical category: A rote learning and word association analysis. Journal of Verbal Learning \& Verbal Behavior, 1, 31-41.

Gordon, B., \& CARAmazza, A. (1982). Lexical decision for open- and closed-class words: Failure to replicate differential frequency sensitivity. Brain \& Language, 15, 143-160.

Gordon, B., \& CARAmazza, A. (1983). Closed- and open-class lexical access in agrammatic and fluent aphasics. Brain \& Language, 19, 335-345.

Gordon, B., \& CARAmazzA, A. (1985). Lexical access and frequency sensitivity: Frequency saturation and open/closed class equivalence Cognition, 21, 95-115.

GreEnBERG, S., \& Koriat, A. (1991). The missing-letter effect for common function words depends on their linguistic function in the phrase Journal of Experimental Psychology: Learning, Memory, \& Cognition, 17, 1051-1061.

Grosjean, F., \& Gee, J. P. (1987). Prosodic structure and spoken word recognition. Cognition, 25, 135-155.

Haber, R. N., \& Schindler, R. M. (1981). Errot in proofreading: Evidence of syntactic control of letter processing. Journal of Experimental Psychology: Human Perception \& Performance, 7, 573-579.

Haberlandt, K., \& Graesser, A. C. (1989). Buffering new information during reading. Discourse Processes, 12, 479-494.

HEALY, A. F. (1994). Letter detection: A window to unitization and other cognitive processes in reading text. Psychonomic Bulletin \& Review, 1, 333-344.

Henderson, J. M., \& Ferreira, F. (1993). Eye movement control during reading: Fixation measures reflect foveal but not parafoveal processing difficulty. Canadian Journal of Experimental Psychology, 47, 201-221.

Holmes, V. M., \& O'Regan, J. K. (1981). Eye fixation patterns during the reading of relative-clause sentences. Journal of Verbal Learning \& Verbal Behavior, 20, 417-430.

INHOFF, A. W. (1984). Two stages of word processing during eye fixations in the reading of prose. Journal of Verbal Learning \& Verbal Behavior, 23, 612-624.

INHOFF, A. W., \& RAYNER, K. (1986). Parafoveal word processing during eye fixations in reading: Effects of word frequency. Perception \& Psychophysics, 40, 431-439.

JosHI, A. K. (1985). Processing of sentences with intrasentential codeswitching. In D. Dowty, L. Kartunnen, \& A. Zwicky (Eds.), Natural language parsing (pp. 190-204). New York: Cambridge University Press.

KOHLER, W. (1929). Gestalt psychology. New York: Liverright.

KoLK, H. H. J., \& BLOMERT, L. (1985). On the Bradley hypothesis concerning agrammatism: The nonword-interference effect. Brain \& Language, 26, 94-105.

Koriat, A., \& Greenberg, S. N. (1991). Syntactic control of letter detection: Evidence from English and Hebrew nonwords. Journal of Experimental Psychology: Learning. Memory, \& Cognition, 17, 1035-1050.

Koriat, A., \& GReEnBerg, S. N. (1994). The extraction of phrase structure during reading: Evidence from letter detection errors. Psychonomic Bulletin \& Review, 1, 345-356.

Koriat, A., \& Greenberg, S. N. (1996). The enhancement effect in letter detection: Further evidence for the structural model of reading. Journal of Experimental Psychology: Learning, Memory, \& Cognition, 22, 1184-1195.

LAPOINTE, L., \& DELL, G. (1989). A synthesis of some recent work in sentence production. In G. Carlson \& M. K. Tanenhaus (Eds.), Linguistic structure in language processing (pp. 107-156). Dordrecht: Kluwer.
LeVelt, W. J. M. (1989). Speaking: From intention to articulation. Cambridge, MA: MIT Press.

MacDonald, M. C., Pearlmutter, N. J., \& Seidenberg, M. S. (1994). On the lexical nature of syntactic ambiguity resolution. $P s y-$ chological Review, 101, 676-703.

Miller, G. A., \& Selfridge, J. A. (1950). Verbal context and the recall of meaningful material. American Journal of Psychology, 63, 176-185.

MORAVCSIK, J. E., \& HEALY, A. F. (1995). Effect of meaning on letter detection. Journal of Experimental Psychology: Learning, Memory, \& Cognition, 21, 82-95.

Morrow, D. G. (1985). Prepositions and verb aspect in narrative understanding. Journal of Memory \& Language, 24, 390-404.

MoRrow, D. G. (1986). Grammatical morphemes and conceptual structure in discourse processing. Cognitive Science, 10, 423-455.

NeELY, J. H. (1991). Semantic priming effects in visual word recognition: A selective review of current findings and theories. In D. Besner \& G. W. Humphries (Eds.), Basic processes in reading: Visual word recognition (pp. 264-336). Hillsdale, NJ: Erlbaum.

O'REgAN, J. K. (1975). Structural and contextual constraints on eye movements in reading. Unpublished doctoral dissertation, University of Cambridge.

O'REGAN, [J.] K. (1979). Eye guidance in reading: Evidence for the linguistic control hypothesis. Perception \& Psychophysics, 25, 501-509.

O'REGAN, J. K. (1980). The control of saccade size and fixation duration in reading: The limits of linguistic control. Perception \& Psychophysics, 28, 112-117.

O'REGAN, J. K. (1992). Solving the "real" mysteries of visual perception: The world as an outside memory. Canadian Journal of Psychology, 46, 461-488.

RapP, B., \& Caramazza, A. (1997). The modality-specific organization of grammatical categories: Evidence from impaired spoken and written sentence production. Brain \& Language, 56, 248-286.

RAYNER, K., \& DUFFY, S. A. (1986). Lexical complexity and fixation times in reading: Effects of word frequency, verb complexity, and lexical ambiguity. Memory \& Cognition, 14, 191-201.

RAYNER, K., \& MCCONKIE, G. W. (1976). What guides a reader's eye movements? Vision Research, 16, 829-837.

RAYNER, K., \& Well, A. D. (1996). Effects of contextual constraint on eye movements in reading: A further examination. Psychonomic Bulletin \& Review, 3, 504-509.

Rayner, K., Sereno, S. C., \& Raney, G. E. (1996). Eye movement control in reading: A comparison of two types of models. Journal of Experimental Psychology: Human Perception \& Performance, 22, 1188-1200.

Reichle, E. D., Pollatsek, A., Fisher, D. L., \& Rayner, K. (1998). Toward a model of eye movement control in reading. Psychological Review, 105, 125-157.

SaINT-Aubin, J., \& Poirier, M. (1997). The influence of word function in the missing-letter effect: Further evidence from French. Memory \& Cognition, 25, 666-676.

SCHMAUDER, A. R. (1992). Grammatical and conceptual features in the mental lexicon: Processing in isolation and in context. Unpublished doctoral dissertation, University of Massachusetts, Amherst.

SCHMAUDER, A. R. (1996). Ability to stand alone and processing of openclass and closed-class words: Isolation versus context. Journal of Psycholinguistic Research, 25, 443-481.

SCHMAUder, A. R., \& Egan, M. C. (1998). The influence of semantic fit on on-line sentence processing. Memory \& Cognition, 26, 1304-1312.

Segui, J., Mehler, J., Frauenfelder, U., \& Morton, J. (1982). The word frequency effect and lexical access. Neuropsychologia, 20, 615-627.

SERENO, S. C., \& RAYNER, K. (1992). Fast priming during eye fixations in reading. Journal of Experimental Psychology: Human Perception \& Performance, 18, 173-184.

ShatTuCK-HufNagel, S. (1987). The role of word-onset consonants in speech production planning: New evidence from speech error patterns. In E. Keller \& M. Gopnik (Eds.), Motor and sensory processes of language (pp. 17-51). Hillsdale, NJ: Erlbaum. 
SHEFFIELD, F. D. (1946). The role of meaningfulness of stimulus and response in verbal learning. Unpublished doctoral dissertation, Yale University.

Sorensen, J. M., Cooper, W. E., \& Paccia, J. M. (1978). Speech timing of grammatical categories. Cognition, 6, 135-153.

Stemberger, J. P. (1982). Syntactic errors in speech. Journal of Psycholinguistic Research, 11, 313-345.

SweET, H. (1891). A new English grammar. Oxford: Clarendon Press. TAFT, M. (1990). Lexical processing of functionally constrained words. Journal of Memory \& Language, 29, 245-257.

Trueswell, J. C., \& Tanenhaus, M. K. (1994). Toward a lexicalist framework of constraint-based syntactic ambiguity resolution. In C. Clifton, L. Frazier, \& K. Rayner (Eds.), Perspectives on sentence processing (pp. 155-180). Hillsdale, NJ: Erlbaum.
Vrru, F. (1991). The influence of parafoveal preprocessing and linguistic context on the optimal landing position effect. Perception \& Psychophysics, 50, 58-75.

\section{NOTE}

1. One sentence in the function word sentence set failed to meet this criterion.

(Manuscript received June 16, 1998; revision accepted for publication December 10, 1999.) 